\title{
A medida de segurança de internação no contexto do Estado Democrático de Direito
}

Patrícia Colombo Ribeiro ${ }^{1}$

\section{Resumo}

\begin{abstract}
A medida de segurança é o tratamento aplicado àqueles indivíduos inimputáveis que cometem um delito penal. A lei diz que o tempo de duração desta medida será indeterminado, até que perdure a periculosidade do agente. A interpretação da medida de segurança conforme os princípios constitucionais penais demonstra que a falta de limite na duração da medida de segurança de internação reflete na não aplicação dos princípios norteadores do Estado Democrático de Direito, principalmente do princípio da Dignidade Humana. Mais ainda, explicita a sua inconstitucionalidade tendo em vista ser a pena de prisão perpétua expressamente proibida pela Constituição Federal.
\end{abstract}

Palavras-Chave: Doente mental; M edida de segurança; Periculosidade; Princípio da Dignidade Humana; Estado Democrático de Direito; Prisão perpétua.

\section{Introdução}

Recente, a medida de segurança é uma resposta criminal sancionatória a certas categorias de delinqüentes sem a capacidade de censurabilidade. Esse instituto é regulado pelo direito penal e baseia-se no conceito de periculosidade tanto para impor ao delinqüente doente a internação em casa de custódia e tratamento psiquiátrico como para liberá-lo de tal situação.

Assim, apesar de o Brasil se proclamar Estado Democrático de Direito, pautado na Dignidade Humana e tendo como norma constitucional a impossibilidade de pena de prisão perpétua, a medida de segurança está subordinada a um juízo de probabilidade. Apenas a probabilidade de o indivíduo voltar a delinqüir autoriza o Estado, utilizando seu ius puniendi, adentrar na esfera individual e privar o indivíduo de sua liberdade, internando-o para tratamento, sob o qual permanecerá até sua cura que, muito provavelmente, não acontecerá, tendo em vista os diversos problemas estruturais e sociais pelo qual passa 0 sistema penal brasileiro.

\footnotetext{
${ }^{1}$ Acadêmica de Direito da UEL
} 


\section{Breve análise do instituto}

No Brasil, até a reforma da parte geral do Código Penal, ocorrida em 1984, prevalecia o critério duplo binário no qual a medida de segurança era aplicada ao agente considerado perigoso pela prática de fato previsto como crime, cuja execução era iniciada após o condenado cumprir a pena privativa de liberdade, ou, no caso de absolvição, após a condenação à pena de multa, depois de passada em julgada a sentença, conforme incisos I e II do art. 82 do Código Penal de 1940 (2006, p. 725). Após a reforma penal, o sistema do duplo binário foi substituído pelo vicariante no qual se aplica a medida de segurança como regra ao inimputável que houver praticado conduta típica e ilícita. Por esse novo sistema, somente é imposta a medida de segurança.

Assim, hoje o inimputável que praticou uma conduta típica e ilícita deverá ser absolvido por prescindir de culpabilidade, sendo-Ihe aplicado medida de segurança. Por ser considerado isento de pena, diz-se que ocorreu uma absolvição imprópria, ou seja, não haverá aplicação de pena ao agente, contudo, a ele será imposto tratamento psiquiátrico a ser cumprido em estabelecimento administrado pelo sistema penal.

João Mestieri (apud D'URSO, 1999, p. 129) elenca como pressupostos desse instituto: a) existência de prévia e expressa previsão legal; b) prática de fato ilícito típico; c) perigosidade do agente.

Muito se questiona, porém, sobre a conduta do inimputável como uma ação criminal, pois o mesmo não teria como valorar os seus atos. No entanto, pela conceituação dada anteriormente, fica evidente que um indivíduo acometido de medida de segurança prescinde da prática de fato típico e ilícito, ou seja, o delito é um marco para a incidência da medida de segurança criminal, enquanto aqueles que não cometeram um crime ficam a cargo de medidas administrativas impostas pelo Estado. Dessa forma, claro está que a existência prévia de um delito é o que separa as medidas de segurança criminais das medidas administrativas. Mas não é só isso, 0 indivíduo deve também apresentar perigo à sociedade para que seja legítima a sua condenação pelo Estado a um tratamento em hospital de custódia e tratamento psiquiátrico.

Para Ferrari (2001): 


\begin{abstract}
A probabilidade na reiteração de um ilícito-típico de acentuada gravidade há de ser, portanto, um dos pontos a serem avaliados na periculosidade penal, servindo como parâmetro para verificar a incidência da medida de segurança criminal, bem como para escolher as espécies de medidas terapêuticas enunciadas pelo legislador. Constatada a probabilidade da repetição de um ilícito-típico, impor-se-á: a) medida de segurança detentiva, quando da prática de um ilítico-típico gravoso; b) medida de segurança terapêutica, não restritiva de liberdade, quando da realização de um ilícito-típico não tão gravoso.
\end{abstract}

Como introduzido pela citação acima, a legislação pátria prevê ao inimputável duas formas de tratamento. Aquela que priva a liberdade de ir e vir do delinqüente insano é uma medida aflitiva e retira o indivíduo da sociedade internando-o em casa de custódia e tratamento psiquiátrico ou, a sua falta, em local adequado. Segundo a Lei de Execução Penal, essa espécie será utilizada quando o crime for apenado com reclusão ou quando o juiz achar necessário. Já as medidas restritivas são aplicadas quando verificado um grau menor de periculosidade e quando o crime é apenado com detenção. Contrariamente a idéia inicial de que esta seria uma alternativa ao tratamento via internação, ao indivíduo é imposto um tratamento ambulatorial, a ser realizado também nos hospitais de custódia e tratamento psiquiátrico, com a permissão de ser cumprido em local diverso desde que apresente dependência médica adequada (M IRABETE, 2007, p. 745).

Ressalta Rogério Greco (2006, p. 728) que há alguns anos a classe médica se mobiliza para evitar a internação de pacientes portadores de doença mental, afirmando que tal procedimento só seria necessário em casos graves de violência com os familiares, com a sociedade ou com eles próprios. Para preservar os direitos dos doentes mentais foi aprovada, em 2001, a Lei 10.216 dispondo sobre a proteção e os direitos das pessoas portadoras de transtornos mentais.

A partir disso, a jurisprudência vem mudando a forma de interpretação do artigo 97 do Código Penal para que a internação seja analisada pelo julgador, sendo-lhe facultado aplicar o tratamento que mais se adapte ao caso, independente da punição que 0 delito receberia, determinando a privação de liberdade somente quando extremamente necessária (BRASIL apud M ARCÃO, 2007, p. 259).

Essa mudança é um avanço importante, visto que um Estado Democrático de Direito, em que se preceitua a dignidade humana como sustentáculo basilar, a medida detentiva só se justifica se tiver como fim um tratamento com fulcro na readaptação do 
doente ao meio social, sob pena de se transformar em depósitos de delinqüentes-doentes, estigmatizados pela periculosidade criminal, que lá ficarão eternamente.

Analisando somente a internação em hospital de custódia e tratamento psiquiátrico, é interessante explicitar que, para ser executada, basta que a sentença de absolvição imprópria transite em julgado e o juiz ordene guia para a execução do internamento. Apesar de simplista na teoria, a prática demonstra grandes complicações diante da ausência de vagas em estabelecimentos específicos.

Renato M arcão (2007, p. 261-264) é claro:

\begin{abstract}
Acometido de moléstia mental, aquele que recebe medida de segurança deverá ser submetido a internação ou tratamento ambulatorial visando sua 'cura'. Ocorre, entretanto, que de regra o tratamento ambulatorial é falho, e a internação, por sua vez, acaba sendo substituída por longo período em cárcere comum no aguardo de vaga em hospital de custódia e tratamento psiquiátrico. Inegável que a situação é caótica e gera constrangimento ilegal. [...]. Conhecendo a realidade prática e sensível às preocupações que dela decorrem, o Tribunal de Justiça do Estado de São Paulo já decidiu que 'estando o réu inimputável encarcerado em cadeia pública há mais de um ano, aguardando vaga para sua internação em hospital de custódia e tratamento psiquiátrico, pode o Magistrado, após a solicitação de exame de cessação de periculosidade, converter a medida em tratamento ambulatorial, ainda que se trate de crime sancionado com reclusão, mormente se 0 delito foi um ato isolado na vida do sentenciado e resultou exatamente de sua perturbação mental, circunstância que possibilita o abrandamento da regra do art. 97 do Código Penal'.
\end{abstract}

Outro problema que ainda está carente de atenção é a indeterminação do prazo máximo de execução da medida de segurança. Tanto a internação como o tratamento ambulatorial perdurará por tempo indeterminado, existindo enquanto não for averiguada a cessação da periculosidade, a qual deverá acontecer entre um e três anos.

Diante disso, é incontestável que desde 1984 não há mudanças no instituto da medida de segurança criminal. Ocorre, todavia, que em 1988 o Brasil promulgou uma nova ordem constitucional, instituindo o Estado Democrático de Direito e elegeu como norte do ordenamento jurídico a dignidade da pessoa humana.

\title{
0 direito penal e o Estado Democrático de Direito
}

0 artigo 1을 da CF estabelece que o Brasil é um Estado Democrático de Direito realizado pela junção da vontade popular com as garantias individuais e limitações do poder do Estado. Por conseqüência, pode-se afirmar que é dever do Estado propiciar uma efetiva 
defesa e proteção dos direitos humanos, com a convivência pacífica numa sociedade justa e solidária, tendo por rumo sempre a dignidade da pessoa humana. Como ensina Chaves de Camargo (2002, p. 49-50):

Toda pessoa humana, pela condição natural de ser, com sua inteligência e possibilidade de exercício de sua liberdade, se destaca na natureza e se diferencia do ser irracional. Estas características expressam um valor e fazem do homem não mais um mero existir, pois este domínio sobre a própria vida, sua superação, é a raiz da dignidade humana. Assim, toda pessoa humana, pelo simples fato de existir, independentemente de sua situação social, traz na sua superioridade racional a dignidade de todo ser. Não admite discriminação [...]

Como nenhum indivíduo pode viver isoladamente, pelo contrário, deve conviver no meio social, sua dignidade ganha contexto social, juntamente com o dever de conviver e respeitar tanto a dignidade dos outros, como a sua própria dignidade (NUNES, 2002, p. 51). Nesse aspecto, o Estado Democrático de Direito passa a ter um papel crucial na defesa da dignidade do homem, como garantidor do respeito a esse valor supremo. 0 princípio da dignidade da pessoa humana coloca o homem como fim e não como meio da atividade estatal. É dever de o Estado protegê-lo em relação ao próprio Estado e em relação aos demais indivíduos, buscando igualdade e respeito mútuo. É dever de o Estado proporcionar condições para que as pessoas se tornem dignas. Este princípio condena todo e qualquer tipo de práticas de tortura, racismo e humilhações. Dessa forma, o Estado tem na condição humana uma barreira intransponível a qualquer construção oriunda do consenso social ou da vontade do Estado (OLIVEIRA, 2007).

Como já exposto, o princípio da dignidade humana está presente em todo o ordenamento, mas ele tem uma importância ímpar quando se trata do sistema penal, pois, muitas vezes, os condenados são colocados à margem social e precisam ainda mais da tutela estatal para ver garantido seus direitos básicos, uma vez que o cometimento de um delito, seja ele de qualquer gravidade, não retira do infrator sua dignidade, pois como já explicitado, esta Ihe é inata e irrenunciável. Em seu artigo, Thiago Almeida de Oliveira (2007) traz de forma clara e objetiva as limitações sofridas pelo Estado enquanto detentor do jus puniendi para que seja respeitado o princípio da dignidade humana. Diz ele:

[...] um dos principais destinatários da norma de respeito à dignidade humana é, sem sombras de dúvidas, o próprio Estado. A supremacia de seus poderes 
constituídos jamais poderá significar, sob qualquer pretexto, sua "indiferença" ou a violação desta dignidade. É nesse sentido que o sistema penal, braço repressivo estatal, sempre terá a dignidade humana como limite intransponível. É a partir daqui que nos permitiremos penetrar em considerações mais minuciosas acerca do vigente sistema penal, como apoio de setores mais categorizados da doutrina penal contemporânea, particularmente no que toca ao tratamento que confere aos psiquicamente incapazes, para ao final indagarmos: o princípio constitucional da dignidade humana é observado no instante da aplicação e execução das medidas de segurança de internação? [...] (OLIVEIRA, 2007).

No que tange ao sistema penal, o princípio da dignidade humana dá o tom para que o condenado veja assegurados seus direitos fundamentais como cidadão e como pessoa, ou seja, o condenado, como ser humanamente digno possui direito e garantias fundamentais. Nesse sentido, expressa Bitencourt (2002, p. 311) “[...] a medida de segurança e a pena de prisão constituem duas formas semelhantes de invasão da liberdade do indivíduo pelo Estado, e, por isso, todos os princípios fundamentais e constitucionais aplicáveis à pena devem aplicar-se também as medida de segurança".

Mas infelizmente, como se explicitará adiante, não ocorre desse modo, havendo discrepantes diferenças entre os direitos assegurados ao condenado à pena e ao condenado à medida de segurança.

\section{Direitos fundamentais do condenado à pena}

Os direitos fundamentais daqueles que cometem um ilícito-típico penal estão previstos tanto no corpo constitucional, como também são encontrados em textos infraconstitucionais.

O Estado está legitimado a punir aqueles que cometem crimes através do jus puniendi, ou seja, o controle social realizado através de punição pré-estabelecida. No entanto, este poder estatal está delimitado pelos direitos fundamentais do condenado.

Em toda a América Latina, a primeira limitação imposta ao sistema penal é o princípio da intervenção mínima (ZAFFARONI, 2007, p. 74), também conhecido como ultima ratio. Ele orienta e limita o poder incriminador do Estado, preconizando que uma conduta só é passível de criminalização quando este for o único meio para proteger a tutela de um bem jurídico. Caso existam outras formas de evitar ou sancionar o dano, a intervenção estatal no âmbito penal fica obrigatoriamente afastada (LOPES, 1999, p. 92). 
Assim, observa-se a busca em preservar a vida e a liberdade do homem e evitar abusos do Estado na esfera da dignidade do homem.

Num próximo passo, o direito penal deve observar o princípio da reserva legal, previsto no artigo 5ำ XXXIX (VADE MECUM, 2008, p. 9) que dispõe: "não há crime sem lei anterior que o defina nem pena sem prévia cominação legal". Segundo esse preceito nenhum fato poderá ser considerado crime sem que antes haja uma previsão em lei, bem como nenhuma pena poderá ser aplicada ao indivíduo se a mesma não estiver estipulada anteriormente. Com o princípio da reserva legal, tanto a descrição da conduta como a conseqüência jurídica da infração devem ser claras, determinadas e definidas previamente por lei formal, assim entendida como "ato normativo emanado do Congresso Nacional elaborado de acordo com o devido processo legislativo constitucional" (MORAES, 2004, p. 72).

Essa norma tem por função limitar a atuação do poder estatal no que tange ao poder exercido sobre as liberdades individuais, conforme esclarece Francisco de Assis Toledo (1994, p. 22):

[...] funda-se na idéia de que há direitos inerentes à pessoa humana que não são nem precisam ser outorgados pelo Estado. Sendo assim, e como não se pode negar ao Estado o poder de estabelecer certas limitações ou proibições, o que não estiver proibido está permitido (permittitur quod non prohibetur). Daí a necessidade de editarem-se proibições causuísticas, na esfera penal, o que, segundo o princípio em exame, compete exclusivamente à lei.

Uma vez respeitado o princípio da reserva legal, o Estado deve também observar o tempus regit actum, norma constitucional descrita no artigo 5ํ, XL (VADE MECUM, 2004, p. 9) "a lei penal não retroagirá , salvo para beneficiar o réu", também chamado de princípio da irretroatividade da lei penal. Com o objetivo de preservar o princípio da legalidade e anterioridade da lei penal, por essa norma prevalece a lei penal vigente na data do fato delitivo, exceto se a nova lei beneficiar o réu.

Nesta esteira, é também garantia fundamental do condenado uma punição adequada, conforme estabelece o princípio da proporcionalidade, consistindo na necessidade de realização de um juízo de adequação entre a medida abstrata imposta pelo legislador e a imposição concreta a ser decretada pelo julgador, considerados os aspectos da gravidade do fato praticado e da lesão ao bem jurídico protegido. Isso é visto, exatamente, 
para que o ser humano possa ter a garantia de que sua punição será ajustada a sua conduta, não podendo sofrer agressões superiores a sua dignidade.

Agregado a isso, existe o princípio da culpabilidade, nullum crimen sine culpa. A culpabilidade deve ser compreendida como fundamento e limite da pena, referindo-se ao caráter inviolável da dignidade do homem. Quando compreendida como fundamento verifica se é possível a aplicação de uma pena àquele que é considerado autor do fato típico e antijurídico, observando a existência dos requisitos caracterizadores, quais sejam, a capacidade culpável, a consciência da ilicitude e a exigibilidade de conduta diversa. Já quando funcionar como limite da pena, visa impedir que a sanção imposta seja aquém ou além da prevista para aquele tipo de delito e circunstâncias do crime e do sujeito (LOPES, 1999, p. 99). No Brasil, esse princípio é elevado ao nível constitucional (art. 5o XLV) (VADE MECUM , 2004, p. 9), tanto quando se fala em dignidade da pessoa humana, como quando menciona a prevalência dos direitos humanos, e ainda quando garante a inviolabilidade dos direitos a liberdade e a igualdade (LOPES, 1999, p. 100).

Não menos importante, o princípio da humanidade garante a liberdade e 0 estado digno do condenado, pois sustenta que o poder punitivo do Estado não pode aplicar sanções que afrontem a dignidade da pessoa humana ou que lesionem a constituição físico-psíquica dos condenados. É por esse princípio que se proíbem a aplicação de penas cruéis, desumanas, humilhantes ou perpétuas e de morte. Também é por meio dele que não se pode utilizar torturas e maus-tratos em interrogatórios policiais, bem como deve Estado gozar de boa infra-estrutura carcerária para atender à finalidade de reeducação e reinserção social (LOPES, 1999, p. 103).

Nesse sentido, a Constituição estabelece como fundamento do Estado de Direito Democrático, a dignidade da pessoa humana (art. 1이 III, CF) dispondo, ainda, expressamente que: "a lei punirá qualquer discriminação atentatória dos direitos e liberdades fundamentais" (art. 50, XLI, CF); "não haverá penas a) de morte, salvo em caso de guerra declarada, nos termos do artigo $84, \mathrm{XIX}$; b) de caráter perpétuo; c) de trabalhos forçados; d) de banimento; e) cruéis" (art. 50, XLVII, CF); "é assegurado aos presos o respeito à integridade física e moral" (art. 5, XLIX, CF) (VADE M ECUM , 2004, pp. 8-10).

Não se pode olvidar que outros princípios são importantes no sentido de garantia da preservação física, psíquica e moral do condenado. Vale ressaltar, ainda, que o jus 
puniendi do Estado também seja aplicado aos condenados à medida de segurança e, portanto, os mesmos princípios expostos anteriormente deveriam nortear igualmente esses condenados, sem quaisquer ressalvas. No entanto, várias diferenças são notadas quando se transferem essas garantias àquele que é imposta medida de segurança.

\section{Direitos fundamentais do condenado à medida de segurança}

Como averiguado até aqui, as medidas de seguranças são aplicadas pelo Estado, por meio do jus puniendi, sistematizadas e conduzidas pelo direito penal.

Zaffaroni e Pierangeli (2007, p. 731) resumem:

[...] as leis penais impõem um controle formalmente penal, e limitam as possibilidades de liberdade da pessoa, impondo o seu cumprimento, nas condições previamente fixadas que elas estabelecem, e cuja execução deve ser submetida aos juízes penais. A forma penal desta coerção compromete grandemente a liberdade das pessoas a ela submetidas. Preocupa, sobremaneira, a circunstância de não terem as 'medidas' um limite fixado na lei e ser sua duração indeterminada, podendo 0 arbítrio dos peritos e dos juízes decidirem acerca da liberdade de pessoas que, doentes mentais ou estigmatizadas como tais, sofrem privações de direitos, ainda maiores do que aquelas que são submetidas às penas. 0 problema não é simples, e a pouca atenção que geralmente se dá as medidas de segurança, do ponto de vista dogmático, torna-a bastante perigosa pra as garantias individuais.

Essa preocupação dos juristas citados tem grande importância, pois na prática é exatamente o que acontece.

Ao se aplicar o princípio da reserva legal, entende-se que ninguém será submetido à medida de segurança sem anterior previsão legal, elegendo a lei como fonte primária e indispensável para a imposição da medida. Segundo Ferrari (2001, p. 94-95):

Diante do princípio da legalidade, não pode o Estado interferir indefinidamente no sagrado direito da liberdade do cidadão, devendo haver um limite máximo temporal pré-definido. A nosso ver, inconstitucional configura-se a ausência de limites máximos de duração às medidas de segurança criminais, afrontando a certeza jurídica e o Estado de Direito, em plena violação ao art. 50 XLVII letra b, combinado com a cláusula pétrea enunciada no art. $60 \cong 4$ da Carta Magna.

No mesmo sentido, Luiz Flávio Gomes (1993, p. 62-80) afirma que todos os cidadãos

- imputáveis ou inimputáveis - têm o direito de saber, previamente, a exata natureza e duração das sanções penais que lhes serão impostas. 
No entanto, o parágrafo 10 do art. 97 do Código Penal (VADE M ECUM 2004, p. 557) explicita que a medida de segurança prevalecerá enquanto não for constatada por perícia médica a chamada cessação de periculosidade. Assim sendo, quaisquer das espécies das medidas de segurança podem durar indeterminadamente, podendo ser mantidas, em alguns casos, até o falecimento do agente. Por esse motivo, doutrinadores têm defendido a idéia de que esse artigo viola alguns preceitos constitucionais, entre eles o que veda a pena de prisão perpétua, principalmente quando se tratar de medida de segurança de internamento. Nas lições de Zaffaroni e Pierangeli (2007, p. 729) "não é constitucionalmente aceitável que, a título de tratamento, se estabeleça a possibilidade de uma privação de liberdade perpétua, como coerção penal".

Diante disso, há uma nova tendência atual em sustentar que a medida de segurança não pode ultrapassar o limite máximo da pena abstratamente cominada ao delito, pois aí estaria o limite do jus puniendi do Estado na esfera da liberdade individual, independente do Código Penal, uma vez que a norma constitucional prevê essa limitação.

André Copetti (apud GRECCO, 2006, p. 730) chega a afirmar a irregularidade da lei penal:

[...] é totalmente inadmissível que uma medida de segurança venha a ter uma duração maior que a medida da pena que seria aplicada a um imputável que tivesse sido condenado pelo mesmo delito. Se no tempo máximo da pena corresponde ao delito 0 internado não recuperou sua sanidade mental, injustificável é a sua manutenção, devendo, como medida racional e humanitária, ser tratado como qualquer outro do ente mental que não tenha praticado qualquer delito.

No mesmo sentido é a posição de Rogério Greco (2006, p. 730) ao argumentar

Cientes de que o Estado não fornece 0 melhor tratamento para seus doentes, devemos deixar de lado o raciocínio teórico e ao mesmo tempo utópico de que a medida de segurança vai, efetivamente, ajudar o paciente na sua cura. Muitas vezes o regime de internação piora a condição do doente, o que justifica a edição do novo diploma legal que proíbe a criação de novos manicômios públicos.

No entanto, o Supremo Tribunal Federal entende que basta restringir a duração da medida ao máximo de 30 anos para que tanto a garantia constitucional disposta no artigo 50 $\mathrm{XLVII}, \mathrm{b}$, como o princípio da dignidade humana, estejam plenamente respeitados: "A 
interpretação sistemática e teleológica dos arts. 75, 97 e 183, os dois primeiros do Código Penal e o último da Lei de Execução Penal, deve fazer-se considerada a garantia constitucional abolidora das prisões perpétuas. A medida de segurança fica jungida ao período máximo de trinta anos (RT 842/470)" (MIRABETE, 2007, p. 740).

Também Ferrari (2001, p. 95) volta seu pensamento para a idéia da não distinção, afirmando que "ambas as sanções fulcram-se em razões de segurança jurídica possuindo como premissa obrigatória e prévia, a prática da infração penal, na qual tanto a espécie da medida de segurança como a quantidade da sanção deve ser conhecida".

Essas desigualdades também são sentidas no caso do princípio da irretroatividade, pois enquanto para os imputáveis e semi-imputáveis é possível na retroatividade da lei para favorecer o réu, para muitos juristas e julgadores esse benefício não se estenderia ao internado por medida de segurança.

Toledo (1994, p. 40), citando a expressão utilizada pelo ministro Francisco Campos na Exposição de motivos do Código Penal, acredita que é assegurado ao internado por medida de segurança o princípio da legalidade, mas não se aplica a retroatividade legal, uma vez que a medida de segurança não se confunde com a pena e, portanto, deve ser regida pela lei vigente ao tempo da sentença, ou pela que suceder durante a execução.

Já defendendo a aplicabilidade do princípio da retroatividade benéfica ao sancionado com medida de segurança, temos os doutrinadores Luiz Vicente Cernicchiaro e Paulo José Costa Junior (apud FERRARI, 2001, p. 96), afirmando:

[...] rigorosamente o princípio da irretroatividade da lei é corolário do princípio da legalidade. Evidente, portanto, que se a finalidade do princípio é impedir punição sem prévia definição do ilícito, não faz sentido conceder que o Estado promova a definição depois da ação. Praticamente seria como se a definição não antecedesse ao fato. Daí o enunciado - praevia legi.

Seguindo a idéia acima exposta e tendo em vista que em sua substância pena e medidas de segurança não possuem diferenciação alguma - visto que ambas têm caráter aflitivo e não são aptas a recuperar ou tratar os delinqüentes, apenas sancionando-os -, não há motivação lógica e legal para que haja tal diferenciação, devendo o princípio da irretroatividade da lei ser aplicado igualmente à pena e à medida de segurança, uma vez que é princípio constitucional e, portanto, deve incidir em toda norma material do direito penal. 
Outro princípio que deve ser totalmente observado é o princípio da proporcionalidade, compreendido como proibição do excesso. Citado por Ferrari, Reale Junior (apud FERRARI, 2001, p. 101) ensina:

[...] o princípio da proporcionalidade deflui do conjunto de princípios e direitos fundamentais explícitos na Constituição, a começar pelo princípio da dignidade da pessoa humana. Emana, portanto, da proibição de penas cruéis, da determinação da individualização da pena que importa, no primeiro momento, em uma individualização legislativa de acordo com a natureza do bem jurídico tutelado e depois, quando da sentença, na busca da pena justa e proporcional à gravidade do fato e à cul pabilidade do agente. Constitui uma característica de um Estado Social e Democrático de Direito devendo a cominação e a aplicação da medida de segurança criminal serem proporcionais à gravidade do ilícito questionando-se a ilimitada perpetuidade temporal, vez que, configurada como qualquer outra sanção criminal, ofende e atinge de modo categórico a dignidade do cidadão, a violar 0 art. 10 de nossa Constituição Federal.

Em suma, a medida de segurança deve ser necessária, adequada e suficiente. Por essa norma, o juiz deve aplicar a espécie de tratamento mais eficaz e menos prejudicial tanto ao insano como à sociedade. Como ensina Dias (apud FERRARI, 2001, p. 104), o princípio da proporcionalidade em sentido estrito possui como características:

[...] proibir a aplicação de uma medida de segurança que se revele, na carga de negação ou de restrição de direitos fundamentais do agente que representa, desajustada, desproporcional, desmedida ou excessiva frente à gravidade do ilícito típico e à perigosidade do agente.

Complementando essa idéia, o princípio da intervenção mínima, cuja maior manifestação recente no Brasil se deu com a criação dos juizados especiais criminais, explicita que essa norma deve ser estendida ao delinqüente que possui moléstia mental. Primeiro porque negar 0 benefício da transação penal àquele que nem sequer foi considerado ainda inimputável seria o mesmo que admitir a presunção de periculosidade, afrontando tanto a legislação penal como a Constituição Federal. Depois, porque o que permite 0 acesso a esse benefício é o crime de pequeno potencial ofensivo e não quem 0 praticou (FERRARI, 2001, p. 114).

Tudo 0 já exposto também se justifica pela averiguação do princípio da igualdade, observado o seu aspecto formal e material. Juarez Tavares (apud FERRARI, 2001, p. 124) destaca "seria atentatório à dignidade humana que uma lei dispensasse o mesmo 
tratamento aos mentalmente sadios e enfermos, figurando como inconstitucionais leis que apliquem maior sofrimento aos desiguais".

Por fim, não se pode esquecer do princípio da dignidade humana que, como já explicitado, exige das autoridades condições mínimas no tratamento dos doentes submetidos à medida de segurança.

Diante do exposto, fica evidente a discrepância de tratamento dado pelo Estado, no exercício do jus puniendi, ao criminoso dito normal e àquele que é considerado doente mental. Questionam-se, então, quais são as diferenças e/ou semelhanças existentes entre a medida aplicada ao primeiro tipo de criminoso - pena - e a aplicada ao segundo - a medida de segurança.

Pena versus medida de segurança

Muitos são os que elencam as diferenças e semelhanças entre pena e medida de segurança, mas praticamente ninguém se dá ao trabalho de verificar atributos essenciais para embasar suas conclusões. Isso fica muito claro ao analisar as opiniões e conclusões dos juristas citados abaixo.

Segundo Hungria e Fragoso (1978, p. 11-13), pena e medida de segurança se diferem por apresentar finalidades e formas de execução distintas. A pena aplica-se exclusivamente aos responsáveis e funda-se na culpabilidade, sendo imposta como sanção a um fato concreto e passado - crime -, com caráter retributivo, aflitivo e proporcional ao delito. A medida de segurança, por sua vez, aplica-se aos irresponsáveis e semi-responsáveis com fundamento na periculosidade e baseada num tratamento pedagógico.

Ou seja, pena e medida de segurança possuem certas diferenças, o que é normal entre espécies diversas. Todavia, elas têm também muitas características em comum, demonstrando que são sim espécies distintas, mas pertencentes ao mesmo gênero, no caso em tela, denominado sanção penal.

Nesse sentido, Luiz Flávio Gomes (apud D’URSO, 1999, p. 126-127), escreveu:

A pena, tradicionalmente, independente da discussão que existe em torno de sua finalidade de seu sentido - retributiva e/ou preventiva - sempre foi vista como um mal, previsto pelo Direito Penal para o caso de cometimento de um fato punível; a medida de segurança, por sua vez, não é vista normalmente como um mal, mas sim como tratamento destinado a evitar que o criminoso perigoso volte a delinqüir. 
Ocorre que nenhum tratamento é possível sem a privação ou restrição de direitos da pessoa que será tratada; desse modo, não há como negar o caráter aflitivo das medidas, não há como negar que elas também constituem um mal necessário (necessário para a cura, necessário para a sociedade, mas inegavelmente um mal). As medidas de segurança, em suma, tal como a pena, implicam na privação ou restrição de direitos fundamentais da pessoa [...] Fazendo-se abstração do sentido ou finalidade das penas e das medidas elas se identificam, dentre outros, neste ponto: possuem ambas caráter aflitivo, é dizer, é da essência delas a privação ou restrição de direitos fundamentais. E o grave (nem sempre posto em destaque) é que as medidas, do modo como estão disciplinadas no Código Penal brasileiro, podem ser muito mais graves que a pena, pois elas são (injustamente) indeterminadas. Em verdade, penas e medidas são diferentes mais na aparência que na essência: constituem, ambas, 'medidas de defesa social'; não passam de duas formas de controle social, por isso que a jurisprudência alemã já tende a não ver diferenças entre elas. Exatamente porque ambas constituem formas de controle social, devem obviamente ser limitadas, regulamentadas. E porque substancialmente configuram formas de invasão do poder estatal na liberdade do homem, todas as garantias que cercam as penas valem automaticamente para as medidas de segurança.

Assim, no modelo atual, pena e medida de segurança são formas diferentes de sanção penal aplicadas pelo Estado por meio do jus puniendi, e, conseqüentemente, deveriam estar sujeitas aos mesmos direitos fundamentais. Ocorre, todavia, que tanto a legislação pátria como as interpretações dada por alguns julgadores e juristas não caminham nessa direção, contrariando explicitamente o princípio da dignidade humana e, por conseqüência, os preceitos do Estado Democrático de Direito.

Essa divergência de entendimentos acontece principalmente pela disposição e localização do instituto da medida de segurança no ordenamento jurídico, que a trata como medida criminal e não como medida administrativa, apesar de impor a ela uma série de restrições que não cabem dentro do Direito Penal em que a mesma está inserida. Conforme entende Zaffaroni e Pierangeli (2007, p. 731) “não se pode considerar 'penal' um tratamento médico e nem mesmo a custódia psiquiátrica. Sua natureza nada tem a ver com pena que desta se diferencia por seus objetivos e meios".

Vê-se, então, que o Estado, na tentativa de proteger tanto a sociedade como 0 próprio doente mental, acaba por violar os preceitos do Estado Democrático de Direito. Isso decorre, principalmente, porque a periculosidade é um juízo de probabilidade e não de certeza, e o Estado teme pela soltura do delinqüente doente mental. Além disso, se existir um limite temporal na duração da medida de segurança, o governo, obrigatoriamente, teria de encontrar respostas rápidas e eficazes para os seguintes problemas que emergem: o que 
fazer com o louco que no fim do prazo da medida de segurança não se curou? (GOMES, 2007) Pode o Estado impor a ele interdição e/ou internamento em hospital psiquiátrico da rede pública? Nesse caso, haveria uma ação cível de interdição, independente do princípio da disponilibilidade da ação? E se a sentença fosse negativa? Pode o Estado simplesmente deixá-lo na responsabilidade dos familiares como ocorria na Roma antiga? (PANTALEÃO, 2007)

Diante de tantas incertezas e suscitações, não é difícil entender porque os dispositivos legais da medida de segurança não são alterados desde 1984.

Tentando minimizar as conseqüências, alguns poucos julgados explicitam que:

[...] com base no artigo 75 do Código Penal e 183 da Lei de Execução Penal, a medida de segurança está limitada à duração da pena imposta ao réu e que, mesmo persistindo a doença mental e havendo necessidade de tratamento, após a declaração de extinção da punibilidade, este deve ocorrer em hospital psiquiátrico cessada a custódia (BRASIL apud GOM ES, 2007).

Diante disso, D’urso (1999, p. 133) conclui:

[...] somente quando se conseguir destacar a medida de segurança da esfera penal, remetendo-a, definitivamente, para a esfera da saúde, é que se poderá esperar que a medida possa cumprir sua finalidade, a de tratar o homem doente, para que não volte a delinqüir.

Dessa forma, enquanto a medida de segurança estiver na esfera criminal, o Estado necessita do exercício de seu jus puniendi para sancionar o delinqüente mentalmente enfermo e por isso, deve respeitar os princípios fundamentais assegurados a qualquer pessoa que cometa um delito.

\section{A medida de segurança de internação no contexto do Estado Democrático de Direito}

A Constituição Federal coloca a preservação da dignidade do homem como uma das razões do Estado Brasileiro. Para concretizar esse objetivo, concorrem outros preceitos normativos que mostram ao interprete o delineamento dessa proteção, como por exemplo, 0 artigo 5, XLVII, "b" que estatui "[...] não haverá penas [...] de caráter perpétuo". Com essa disposição, o constituinte revela que sofrer incidência indeterminada da medida de 
segurança é indigno ao homem (OLIVEIRA, 2007). Essa imposição constitucional aliada ao fato da medida de segurança está situada dentro do sistema penal enquanto sanção criminal - como já concluído anteriormente -, demonstra que 0 atual sistema de aplicação de medida criminal no Brasil viola os direitos humanos e contraria preceito constitucional. Como salienta Oliveira (2007):

Em um país regido por uma Constituição que eleva a tutela da dignidade humana a princípio fundamental do Estado, chegando a especificar, mais adiante no texto constitucional que a incidência indeterminada de uma sanção penal sobre uma pessoa (e já pudemos concluir em tó pico próprio, que não há diferenças reais entre penas privativas de liberdade e medidas de segurança de internação) viola a dignidade humana, o raciocínio nos conduz a uma conclusão quase algébrica: a indeterminação de duração do prazo das medidas de segurança de internação (com a desinternação condicionada a um laudo que afirme a cessação da periculosidade) colide com a norma fundamental brasileira; 0 art. $97, \S 10$, do Código Penal, por inconstitucional, há de ser considerado não recepcionado pela vigente ordem constitucional.

Não se discute nesses casos o que fazer com o indivíduo em que comprovadamente persiste doença que o torne propenso a ofender bens jurídicos tutelado, questão extremamente delicada e que deve ser solucionada com medidas administrativas por parte do poder público. Apenas afirma que não cabe mais a esfera penal intervir na liberdade de qualquer pessoa restrito somente por uma condição que pode nunca se realizar.

Nesse sentido, Zaffaroni e Pierangeli (2007, p. 733) buscam uma alternativa:

[...] é mister reconhecer-se para as medida de segurança o limite máximo da pena correspondente ao crime cometido [...]. Se [...] continuar a doença mental da pessoa submetida à medida, a solução é comunicar a situação ao juiz do cível ou ao M inistério Público, para que se proceda conforme 0 art. 1.769 do Código Civil em vigor e efetivar a internação nas condições do art. 1.777 desse mesmo Código.

Assim, enquanto esse assunto continuar situado na esfera penal, entende-se que 0 mais correto seria que o criminoso inimputável fosse condenado (e não absolvido impropriamente) a sanção determinada, tomando por base a pena abstrata cominada ao delito, como prescreve o princípio da reserva legal, uma vez que praticou um fato típico e ilícito. No entanto, por prescindir de culpabilidade, não lhe seria aplicada a sanção penal chamada pena, mas aquela denominada medida criminal, que difere da primeira apenas 
pela forma de execução, qual seja, o tratamento, e não pela não aplicação dos princípios fundamentais do condenado.

É também fundamental que ao internado para tratamento em hospital de custódia sejam aplicados os demais benefícios penais, entre eles todas as formas de prescrições e liberdades condicionadas.

Com a intensificação da luta pelos direitos humanos no mundo todo, não deve demorar muito para que doutrinadores, legisladores e julgadores possam visualizar a situação caótica em que se encontram os psiquicamente incapazes e comecem a efetivar os preceitos do Estado Democrático de Direito. Mas Zaffaroni e Pierangeli (2007, p. 733) advertem "Se a lei não estabelece o limite máximo, é o interprete quem tem a obrigação de fazê-Io".

\section{Conclusão}

A medida criminal surge no direito penal visando à prevenção a novos delitos cometidos pelos mentalmente enfermos, pautada na periculosidade do agente. Primeiramente, cumpre relembrar que a periculosidade é uma probabilidade de reincidência da conduta delitiva e não uma certeza, o que, por si só, já denota subjetividade tamanha, colocando em cheque a legitimidade desse instituto penal. Por outro lado, restou demonstrado que essa imposição é apenas válvula de escape para que o poder público afaste 0 agente do convívio social, pois como 0 delinqüente prescinde de culpabilidade e, portanto, a ele não pode ser imposta pena, tratar foi a forma encontrado para isolá-lo.

Ocorre, todavia, que da mesma forma como ocorre nos presídios brasileiros, os hospitais de custódia e tratamento psiquiátrico também carecem de infra-estrutura, pessoal capacitado, e elementos básicos como medicamentos, para que o doente possa se restabelecer e ter sua periculosidade cessada. É muito interessante notar, ainda, que é exatamente a cessação dessa perigosidade que possibilita a liberação do agente, demonstrando mais ainda a contradição e a falta de regulamentação própria nesse sentido.

Se não bastasse tudo isso, o Estado Democrático de Direito que foi instituído em 1998 e tem como um dos seus objetivos a defesa da dignidade humana, prevê distinções inconcebíveis entre os direitos fundamentais dos condenados à pena e dos condenados à medida de segurança. Esse fato é agravado com a conclusão de que pena e medida criminal 
estão inseridas no mesmo contexto, qual seja, o da sanção penal. Como foi evidenciado, ambas são impostas a quem cometeu fato típico e ilícito pelo Estado que, autorizado pelo jus puniendi, restringe os direitos e garantias fundamentais do indivíduo e interfere em sua liberdade, retirando-lhe da sociedade com o fim de ressocialização.

Diante disso, deve o Estado, enquanto a medida criminal estiver inserida no âmbito penal, observar todas as garantias reservadas tanto àquele a que se impõe pena como ao submetido à medida de segurança, sob pena de abusar de seu poder de punir e contrariar preceitos constitucionais. Ademais, tudo aquilo que o Código Penal e a Lei de Execução Penal estabelecem e que se verificar contrário aos preceitos da nova ordem constitucional, deve ser entendido com não recepcionado e, de forma alguma, ser aplicado pelas autoridades. No caso das medidas criminais de internação deve-se ir mais além, uma vez que deixar a liberdade do indivíduo condicionado à cessação da periculosidade é afrontar o artigo 5o, XLVII, b da Constituição Federal, pois a cura pode não acontecer e a sanção se tornaria perpétua. Mais que isso, o fato de privar o indivíduo eternamente configura violação ao princípio da dignidade humana.

Conclui-se, então, que enquanto o indivíduo que cometeu um crime acometido por transtorno mental estiver sob a esfera penal, a ele deve estar resguardado todos os direitos estabelecidos na legislação, inclusive o direito de saber concretamente por quanto tempo ficará em tratamento. Dessa forma, cabe aos estudiosos do direito, em conjunto com outros ramos do saber que esse tema abrange, sugerirem alternativas ao legislador sobre o que fazer quando 0 indivíduo ainda doente for colocado em liberdade. 0 que não pode ser admitido num Estado de Direito é que alguém fique perpetuamente em tratamento, sob a custódia estatal. Nesse sentido, deve os julgadores irem além do que o Supremo Tribunal Federal recomenda (liberar o indivíduo após 30 anos) e sancionar o delinqüente doente mental de forma proporcional à sua conduta, pois o direito penal deve reprimir 0 ato delituoso e não quem o cometeu, enquanto cabe ao Estado, fora do exercício do jus puniendi, encontrar meios de tratamento, sem invadir de modo agressivo a liberdade e a dignidade humana. 


\section{Referências}

ALM EIDA, Francis M oraes de. Medida de segurança: um debate necessário. In: A crise no processo penal e as novas formas de administração da justiça criminal. Porto Alegre: Notadez, 2006.

BITENCOURT, Cezar Roberto. Código penal comentado. São Paulo: Saraiva, 2002.

BRASIL. Lei 2.848, de 7 de dezembro de 1940. Código Penal. Rio de Janeiro. Diário Oficial da União de 31.12.1940. Disponível em: «ttp:// www.planalto.gov.br/CCIVIL/Decreto-

Lei/Del2848.htm>. Acesso em: 12 jan. 2008

. Projeto de Lei 5.075/01 que altera a LEP. Disponível em:

বhttp://www.planalto.gov.br/ccivil_03/Projetos/PL/2001/msg841-010810.htm>. Acesso em: 14 jan. 2008.

COHEN, Cláudio. A periculosidade social e a saúde mental. Revista Brasileira de Psiquiatria, São Paulo, v. 21, n. 4, 1999. Disponível em: বttp:// www.scielo.br/scielo.php?pid =\$151644461999000400006\&script=sci_arttext>. Acesso em: 24 maio 2007.

D’URSO, Luiz Flávio Borges. Direito criminal na atualidade. São Paulo: Atlas, 1999.

FERRARI, Eduardo Reale. Medidas de segurança e direito penal no estado democrático de direito. São Paulo: Revista dos Tribunais, 2001.

. Duração das medidas de segurança. Revista de Julgados e Doutrina do Tribunal de Alçada Criminal do Estado de São Paulo, São Paulo, n. 5, p. 15-24, jan./mar. 1990.

. Medidas de Segurança e seus limites. Revista Brasileira de Ciências Criminais, São Paulo, v.1, n.2, p.62-80, abr./jun. 1993.

. O louco deve cumprir medida de segurança perpetuamente? Disponível em: বhttp://www.mundolegal.com.br/?FuseAction=Doutrina_Detalhar\&did=15888>. Acesso em: 2 ago. 2007.

GRECO, Rogério. Curso de direito penal: parte geral. 6.ed. Rio de Janeiro: Impetus, 2006. v.1.

HOUAISS, Antônio. Dicionário eletrônico da língua portuguesa. Versão 1.0.5a. São Paulo: Objetiva, 2002. CD-ROM.

HUNGRIA, Nelson; FRAGOSO, Heleno. Comentários ao código penal. Rio de Janeiro: Forense, 1978.

LOPES, M aurício Antônio Ribeiro. Princípios políticos do direito penal. 2. ed. São Paulo:

Revista dos Tribunais, 1999.

M ARCÃO, Renato. Curso de execução penal. 5. ed. São Paulo: Saraiva, 2007. 
MIRABETE, Julio Fabbrini. Comentários à lei n. 7.210/84. 11. ed. São Paulo: Atlas, 2007.

M ORAES FILHO, M arco Antônio Praxedes de. Evolução histórica da imputabilidade penal: uma abordagem cronológica da loucura na humanidade e seus reflexos na legislação criminal brasileira até o código de Piragibe. Jus Navigandi, Teresina, v.10, n. 1071, 14 abr. 2006. Disponível em: «tttp://jus2.uol.com.br/doutrina/texto.asp?id=8234. >. Acesso em: 8 jun. 2007.

NUNES, Luiz Antônio Rizzatto. 0 princípio constitucional da dignidade humana. São Paulo: Saraiva, 2002.

OLIVEIRA, Thiago Almeida de. 0 doente mental, o princípio da dignidade da pessoa humana e a constitucionalização do direito: um urgentíssimo escrutínio (neo) constitucional das medidas de segurança. Universo Jurídico. Disponível em:

বhttp:// www.uj.com.br/Publicacoes/Doutrinas/default.asp?action=doutrina\&iddoutrina=27 37>. Acesso em: 8 jun. 2007.

ORGANIZAÇÃO DAS NAÇÕES UNIDAS - ONU. Proteção de pessoas acometidas de transtorno mental e a melhoria da assistência à saúde mental. Documento das Nações Unidas n. A/ 46/ 49 de 17.12.1991. Disponível em:

বhttp://www.direitoshumanos.usp.br/counter/Onu/Deficiencia/texto/texto_2.html>. Acesso em: 3 abr. 2008

PANCHERI, Ivanira. M edida de segurança. Revista Brasileira de Ciências Criminais, São Paulo, v. 5, n. 20, p.105-112, out./ dez. 1997.

PANTALEÃO. Juliana Fogaça. M edida de segurança e reforma da lei de execução penal. Jus navigandi, Teresina, v. 8, n. 340, 12 jun. 2004. Disponível em: «tttp:// jus2.uol.com.br/doutrina/texto.asp?id=5315>. Acesso em: 24 maio 2007.

PERES, M aria Fernanda Tourinho; NERY FILHO, Antônio. A doença mental no direito penal brasileiro: imputabilidade, irresponsabilidade, periculosidade e medida de segurança. História, ciências, saúde. Rio de Janeiro. v. 9, n. 2, p. 335-355, maio/ago. 2002. Disponível em: <http://www.scielo.br/pdf/hcsm/v9n2/a06v9n2.pdf>. Acesso em: 8 jun. 2007.

REALE Jr, Miguel; DOTTI, René Ariel; ANDREUCCI, Ricardo Antunes; PITOM BO, Sérgio M . de M oraes. Penas e medida de segurança no novo código. Rio de Janeiro: Forense, 1985.

SOUTO, Ronya Soares de Brito e. A (i)legitimidade do processo de imposição das medida de segurança no direito penal brasileiro. Leituras constitucionais do sistema penal contemporâneo. Rio de Janeiro: Lumen Juris, 2006.

SOUZA, Lara Gomides de. 0 caráter perpétuo das medidas de segurança. LFG: Rede de Ensino Luiz Flávio Gomes. Disponível em:

বhttp:// www.lfg.com.br/public_html/article.php?story=20060809115009620>. Acesso em: 24 maio. 2007. 
TOLEDO, Francisco de Assis. Princípios de direito penal. São Paulo: Saraiva, 1994.

VADE Mecum. 5.ed. São Paulo: Saraiva, 2008.

ZAFFARONI, Eugenio Raúl; PIERANGELI, José Henrique. M anual de direito penal brasileiro. 7. ed. São Paulo: Revista dos Tribunais, 2007. 